\title{
Overcoming Barriers of Study Delay by Implementing A Warm Bounded Learning Community
}

\author{
Hester Brauer ${ }^{1} \&$ Miranda de $\mathrm{Hei}^{2}$ \\ ${ }^{1}$ Faculty Social Work \& Education, The Hague University of Applied Sciences, The Netherlands \\ ${ }^{2}$ Faculty Management \& Organisation, The Hague University of Applied Sciences, The Netherlands \\ Correspondence: Miranda de Hei, Research Group Sustainable Talent Development, Faculty Management \& \\ Organisation, The Hague University of Applied Sciences, PO Box 13336, 2501 EH The Hague, The Netherlands. \\ Tel: 31-625-065-072.E-mail: M.S.A.deHei@hhs.nl
}

Received: November 21, 2020

Accepted: December 24, 2020

Online Published: January 5, 2020

doi:10.5539/hes.v11n1p94

URL: https://doi.org/10.5539/hes.v11n1p94

\begin{abstract}
We hypothesise that warm bounded learning communities (WBLC) contribute to social and academic integration of students. Eleven students facing study delay participating in a WBLC to write their bachelor thesis were interviewed. They described important episodes in their graduation process, prior to and during their participation. Results indicate that a WBLC that supports interaction, stimulates the development of a community identity, focuses on student collaboration, and mutual appropriation, guides students believing in student agency and supporting a positive self-belief system, can break down barriers students experience. Characteristics of the implemented WBLC and appropriate teacher roles can enlarge motivation, sense of belonging, academic knowledge and self-efficacy. Social interdependence is an important engine to increase social connections and academic self-efficacy, enhancing the growth of academic skills. Our research indicates that well implemented WBLCs can contribute to social and academic integration of students with a study delay.
\end{abstract}

Keywords: study delay, learning communities, social integration, academic integration, educational design

\section{Introduction}

In the last decades, there has been a major increase of student participation in Higher Education. (Altbach, Reisberg \& Rumbley, 2009). The student population has changed into a more diverse population regarding ethnic background of the students, prior qualifications and academic preparedness (Thomas, 2002). Many of these students fail to complete the final phase of their education within the given time (Ho, Wong, \& Wong, 2010). This study delay results in demotivated students, a lack of student engagement and negative self-efficacy beliefs. Part of the students drop out and enter the job market without a bachelor's or master's degree.

\subsection{Warm Bounded Learning Environment}

For students to successfully complete their higher education programme, they need an environment that is based on caring supportive alliances (Skinner, 2012). Such a warm learning environment provides students with personal and social support, frequent contact in and outside the classroom between student and faculty. Furthermore, such a learning environment invites students to learn together with others (Tinto, 2012; Chickering \& Gamson, 1987). Collaborative learning may contribute to social interaction and learning together in higher education (Fransen, Weinberger \& Kirschner, 2013). Universities have implemented collaborative learning by having students working together in learning communities. Wilson, Ludwig-Hartman, Thornam, and Dunlap (2004) define bounded learning communities (BLCs) as groups of students who collaborate in a structured teaching setting, with mandatory participation. Students mostly are not allowed to choose their group composition. In BLCs students need to make an explicit effort to connect with others and work on shared goals. Members of the community are bound together by the physical environment (environmental interdependence). Within these bounded learning communities students should feel comfortable to share thoughts, ideas and experiences. In learning communities, individual goals are affected by the actions of others (Johnson \& Johnson, 2008). To create a strong community within which individuals encourage and facilitate each other's efforts to complete tasks, teachers should stimulate positive interdependence. Positive interdependence refers to a situation in which individuals recognize that achieving their goals is only possible if others, with whom they are 
collaborating, also achieve their goals.

Bounded learning communities have their own identity shaped by the community's history of heritage, including the shared goals and belief system, rules and norms of the community. When a new generation of members enter the community, this identity assures that the community continues to function (Barab \& Duffy, 2000). The process of sharing, asking questions and discussing leads to joint knowledge building. This new understanding is superior to their individual understanding. Mutual appropriation arises; students of the community are both acting as learners and teachers. All participants add value to the group based on their expertise. Bielaczyc and Collins (1999) refer to the 'diverse-expertise principle', a process during which students develop themselves in areas they are interested in, taking the responsibility to share their expertise with the other members of the community. Role interdependence between students develops. Each student takes complementary and interconnected roles that specify the responsibilities the group needs in order to achieve the mutual goal (Johnson \& Johnson, 2008). Bounded learning communities in which students feel a sense of belonging to the community will boost student retention (Tinto, 1975; Wilson et al., 2004).

In the collaborative process the teacher plays an important role. Teachers establish trusting relationships with students and provide the infrastructure for interaction and work (Wilson et al., 2004). Besides stimulating caring supportive alliances in the community, teachers must create a structured classroom in which they express high expectations of their students; teachers give prompt and effective assessments and feedback; and stress the value of time on task (Tinto, 2012; Chickering \& Gamson, 1987). Teachers must create a setting with autonomy support instructions, where active learning is promoted. They ensure the learning activities relate to past experiences and are applicable to the daily lives of students. Teachers respect and consider the diversity of talents of students, both in difference of talents, and learning styles (Tinto, 2012; Chickering \& Gamson, 1987).

Summarising, for students with a study delay to be successful, a warm bounded learning environment (WBLC) is needed. We define such a WBLC as an environment: 1) in which students collaborate with a strong collective inclusive identity, 2) where participants commit to shared goals, 3) where participants use the diversity-experience to reach goals, 4) where there is respect for the diversity of talents and learning styles, 5) where interaction is based on mutual appropriation, 6) with teachers providing caring supportive alliances, structured classrooms and autonomy support instructions. These characteristics contribute to student engagement and provide a sense of belonging to the community.

\subsection{Striving for Inclusive Education}

Educational sociology approaches explain study delay and dropout from the perspective of inequality at the university, due to different social backgrounds and the failure of university socialization (Georg, 2009). According to Bourdieu's habitus theory, these groups bring different kinds of 'habitus' inside the educational system. Habitus refers to the norms and practices of particular social classes or groups (Bourdieu \& Passeron, 1977). Cultural research describes that students from the dominant social groups have a better habitual fit regarding their own habitus and the institutional habitus. This favourable fit results in social and cultural advantages for social dominant groups. The unfavourable fit for non-traditional students is leading to poor student retention (Thomas, 2002).

In order to provide inclusive education, the challenge for higher education is to bridge the gap between the habitus of the new incoming groups and the institution. In this process, it is necessary to consider student characteristics on learning and working styles, cognitive abilities and capabilities for achievement (Georg, 2009). The institution has to be aware of students' feelings of competence, autonomy and relatedness, which contributes to their academic self-concept, self-efficacy and motivation (Ryan \& Deci, 2000; Skinner, 2012). Student characteristics and needs must be taken into account in the institutional characteristics such as university culture, policies, curriculum, assessment, discipline. Teachers and supporting staff must show their confidence in the study success of their students (Kahu, 2013). Students must achieve successful acculturation with regard to academic and social integration. This integration is a precondition for study success (Georg, 2012). Academic integration can be measured by the quality of grade performance and intellectual development. The more students become adjusted to the intellectual life of the university, the more students will be academically integrated. Social integration refers to the process of students creating mutual relationships and connections. In other words: when students interact frequently with peers and teachers, students grow to be socially integrated. Positive social and academic integration leads to a higher goal commitment and institutional commitment, which reduces the possibility of student drop-out (Tinto, 1997; Thomas, 2002).

By stimulating social and academic integration, higher education can engage a diversity of students, especially students with cultural or educational backgrounds that are not aligned with university culture. Several decades of 
research have demonstrated that student engagement predicts learning, grades, achievement, retention, and graduation (Kahu, 2013; Skinner, 2012). 'Engagement with academic work is defined as constructive, enthusiastic, willing, emotionally positive, cognitively focused participation in learning activities' (Skinner, 2016, p. 150).

\subsection{Hypothesis and Research Question}

In this study we hypothesize that participating in a warm bounded learning community contributes to the social and academic integration of students. We hypothesize that such a learning environment is crucial to transform the disengagement of students with a study delay into an emotionally positive, cognitively focused participation in learning activities.

We formulated our research questions as follows:

(1) 'Which barriers do students with a study delay experience that induce feelings of disengagement?'

(2) 'Which elements of warm bounded learning community contribute to student engagement and the social and academic reintegration of students with a study delay?'

\section{Method}

\subsection{Context}

The Faculty of Social Work and Education of a university of applied sciences in the Netherlands, has developed a new thesis programme, a WBLC for 150 undergraduate students delayed in writing their bachelor thesis. The goal of the WBLC was building a strong community were students reframe themselves by building a positive personal, social and professional identity, resulting in attaining a bachelor's degree. All students who had not been able to acquire a bachelor's degree within five years (four years is the length of a regular trajectory), and who had attained enough credits to start writing their bachelor thesis or already started to do so, were invited to participate in the program. In advance, clear expectations were set for weekly attendance, weekly performance and active participation in the lectures, tutor groups and the digital learning environment. The programme duration was six months.

The WBLC attempted to strengthen social relationships by demanding all participating students to attend university on the same day, in same or adjoining spaces. All individual students were assigned to groups. Students had to attend weekly lectures about research- and writing skills to eliminate deficiencies, complemented with tutor groups consisting of eight students mentored by three alumni (the tutors). The tutor groups were heterogeneous regarding knowledge, skills, talent and progress. The tutor ensured that students interacted to help each other accomplish the task and promote each other's success. Students were asked to take responsibility in providing peer support, encouragement, and assistance to other students' needs to make academic progress. Besides, there was a Facebook community for sharing knowledge, resources and experiences and to encourage each other. The role of the three lecturers was to stimulate a sense of belonging to the community, stimulate the mutual interaction between students, provide knowledge of theories and research skills, work considering the personal ambitions of the student, strengthen the student's self-image and reinforce the collective identity of the group.

\subsection{Participants and Data Collection}

We performed a case study of the WBLC, based on interviews, to explore which elements contribute to student engagement and the social and academic reintegration of students with a study delay. We performed face-to face in depth interviews with 11 out of 150 participants. In this WBLC $85 \%$ of the students were female. The group of respondents consisted of 2 male and 9 females. Ages ranged from 23 till 38 years and the study delay ranged from 1 to 6 years. The respondents were purposively sampled with content variation on the amount of the delay and the level of performance. The participants voluntarily participated in the interviews.

\subsection{Measures and Procedures}

Students where asked in a narrative interview to tell their story from the first time they started with the bachelor thesis till the moment of finishing. The research method was a combination of a Life Story Interview (Atkinson, 1998) and the Critical Incident Technique (Flanagan, 1954).

The interview protocol started with an introduction about the purpose of the research, the duration of the interview, the sequence of the interview and the guarantee of anonymity of the participants. The participants were asked to tell about the most important moments, events, episodes in their bachelor thesis process prior to and during their participation in the WBLC, signalling a significant change in their development. They were asked about the highlights, the downsides and the turning points. They were asked to describe exactly what 
happened, when and where the event took place, who were involved and what the participant thought and felt during these events. After telling their story, respondents were asked about specific topics such as academic integration, social integration, collaborative learning and self-perception. Those topics were based on the concepts from the theory of study delay and warm bounded learning environment.

\subsection{Analyses}

The interviews were audio-recorded and transcribed. First, we identified which parts of the interview contained critical incidents. Second, we explored which of the recurrent themes were related to academic integration, social integration, and student engagement. Special attention was paid to text fragments that related to the belief system, the rituals, the symbols and metaphors that helped shape the local culture of the learning environment. The first author initially identified critical incidents and explored the themes. To avoid pre-set interpretations, the second author checked the identification and coding. In case of disagreement the two authors discussed the results until agreement (cf., Marble, 1997).

\section{Results}

First, we will describe the barriers students experienced during working on their bachelor thesis prior to participating in the WBLC. Those barriers will be outlined on two levels: on a personal level and on an institutional level. Thereafter, we will describe the experience of students participating in the WBLC and what they perceived as stimulating mechanisms to complete their thesis.

\subsection{Barriers Prior to Participating in the WBLC on a Personal Level}

Students experienced competing obligations. They stated that personal issues, such as being pregnant, illness, decease of family members or friends, family matters that need lots of concern, competed regarding time and attention with their study activities. Therefore, their study pace slowed, and they felt detached from the university environment.

Furthermore, they felt they lacked academic skills. Research skills and writing skills were not sufficiently developed according to the students. They experienced problems regarding structuring both the research and the writing process.

'I did not have an overview of what had to be done. I did not know how to process and structure information. That is where it started. I had trouble in conceptually defining the subject.' (B)

Students found it hard to find, read and process literature. When their research plans were turned down by the teacher and they got lots of critical feedback, they experienced that their research skills were inadequate to write a bachelor thesis. Due to this, they experienced feelings of distress and failure. They encountered that they were not sufficiently prepared for these tasks in the previous academic years.

Students described that their image of the professionals they were developing towards, changed during their academic education. They experienced that their future profession was not aligned anymore with their previous expectations.

'During my internship I noticed people spoke negatively about the Social Work study programme. The role of social work in society was diminishing they said. [..] Why should I continue my education for a profession that is changing so much, that the training I received does not prepare me for this task anymore.' $(F)$

Other students indicated that the assignment of the institution they perform their research for, did not align with their personal interest.

'I did not like the assignment I acquired. It was about high school dropouts in a poor neighbourhood. I was not really interested.' (A)

Students stated that their mental resilience diminished. They felt uncertain about their academic knowledge and skills. They lacked confidence in achieving the final goal (finishing their thesis). This lack of confidence grew worse by long-lasting absence of progress and success. This feeling of inferiority was strengthened by social comparison with other students in their classes that were successful. When all deadlines passed, students did not feel an urgency to put a lot of effort in writing anymore.

'When the deadlines have passed, this will become your pitfall, one more month, two more months, what does it matter.' (H)

The longer the delay lasted, the more feelings of embarrassment and guilt students developed towards themselves and their social environment. 


\subsection{Barriers Prior to Participating in the WBLC on Institutional Level}

Students stated that in the academic year after their peers had graduated, the curriculum content was adapted. The courses that prepared students for graduation in their study trajectory were no longer aligned with the new graduation demands.

In the curriculum design students were assigned to a guiding teacher and there was no classroom structure anymore. Students felt they needed to act interdependent and to regulate their own learning. This was what they perceived difficult. The individual route students needed to take to work on their bachelor thesis, made students feel isolated. They were lacking knowledge sharing and emotional support of peers. There was little or no contact with peers and other teachers. They missed being part of a social structure that guided them along the way of their programme.

Students mentioned a lack of support of the guiding teacher. They described the following behaviour of the guiding teacher: 1) too few meetings with the students, 2) feedback consisting of critical remarks only, 3) no directions to improve the product, 4) feedback that was unclear, 5) teachers were not engaged and interested in the project of the student, 6) having insufficient knowledge of the subject or research, and 7) not being accessible for students.

'The teacher would not meet on a weekly base. I could only ask for advice when I finished the thesis as a whole.' (G)

The same student described:

'The meeting was not pleasant. We only talked about what I did wrong, not what was good about the thesis. I feel reluctant towards her guidance. I feared my writing would be criticised again.' (G5)

In the guiding process, students felt stigmatised. Students described being labelled as 'students with a study delay' and they experienced this as negative framing. They felt they were treated different than students that graduated in four years. They mentioned that teachers doubted their qualities and their effort, and doubted that they were capable of graduating. One teacher said according to her student:

'Apparently, you did not do what you had to, otherwise you would not have a study delay'. (F)

Students described they were being looked down upon.

\subsection{Mechanisms of the WBLC to Help Overcome Barriers}

The students who stagnated in their bachelor thesis process started to participate in a new educational environment, the WBLC. In this first year this WBLC was implemented, $69 \%$ of the participants acquired their bachelor's degree.

\subsubsection{Structuring the Learning Environment}

Students described the WBLC as an infrastructure where members are connected by physical and digital environment. Meeting a large group of students who share the same story (of failure) provides a sense of belonging.

'If you enter that room and see how many people are busy graduating, or people who have dropped out and come back to finish it, that gives you a boost of: hey, I'm not alone, we're all together! We can handle it! So that was the first thing that gave me a positive impression, especially because I also met people who were in my class at that time.' (B)

Students were positive that they could apply the knowledge obtained from the lectures, in which research skills were explained and that provided frameworks and guidance, directly in the tutor groups. Furthermore, the tutor groups were used to ask questions.

Students considered the tutor group as pleasant, because fellow students were in the same phase and thus shared the same task. Due to the strict rules regarding presence and involvement, students who were not motivated dropped out in the beginning. The remaining group of students was motivated to achieve deadlines and that gave positive energy, according to the students. Students described that there was a shared sense of urgency and a shared goal (bachelor's degree).

Students mentioned that by offering weekly mandatory classes a renewed school rhythm arose, that made them reconsider competing obligations and again prioritize the study.

'Having a class with peers and a permanent contact moment again, made me actually go to the university to be active.' (C) 
In addition, structure was created by the clear timetables regarding the content of classes and deadlines for tasks that had to accomplished. Students described that the process became clearer and less complex. In addition, students experienced that they were offered structure on content by providing clear substantive guidelines on how to write a bachelor thesis.

\subsubsection{Community}

The community structure was strengthened by the development of a community identity. Students mentioned that a powerful group culture was created through shared values and norms, a motto, rituals and heroes.

Shared values and norms. Students experienced in the community core values and norms, that resound in the attitude of the teachers. Teachers displayed high expectations about the students' performance and were strict about requirements and meeting deadlines. Students praised the teachers approaching students as young professionals who bring in their own individual expertise, and value the complimentary contributions regarding knowledge and resources. Students also appreciated that teachers expressed the confidence that all participants would take part in the graduation ceremony at the end of the programme. Teachers emphasised the importance of having fun along the way.

Motto. In the interviews, students stated that teachers stressed that students should help each other. Students experienced the effect of the motto 'graduation is a jointed experience', which made an appeal to 'we are there for each other and we will do this together'. Students mentioned a climate in which both students and teachers helped each other mutually, a process of shared goals and positive interdependence.

'There was a team sentiment, a common goal, you want yourself and the other person to reach the finish line. We are all going to the European Championship. If I had continued to do it on my own, I would never have made it.' (B)

Rituals. Students experienced the ritual of the weekly start of learning sessions with music and the positive approach of the teacher as stimulating. Students described an enthusiastic atmosphere. Progress was celebrated, and successes were shared in the digital learning environment and the learning meetings. Students mentioned positive summative feedback on their research proposal (receive a 'Go') as a sign of confirmation that they could successfully complete the trajectory. It strengthened the faith in their own ability. A "go" was seen not only as a sign of individual progress, but above all as a sign of progression of collective progress.

'When I was participating in the WBLC and I did not have a go yet, and I saw others who had already had received the go, in a certain way I felt proud of the others and the feeling of us all working well.' (E)

Making the individual and collective progress visible, nourished the conviction that students who take part in the WBLC would attain their Bachelor thesis. A student said:

'I actually saw hope. I thought: oohh, there is still hope. I can participate. This is a sign that it is still possible.' (D)

Students mentioned that the community structure lead to a sense of belonging, a belief in feasibility (self-efficacy). This increased the enjoyment in the graduation process.

Heroes. Students stated that their tutors were giving them hope and faith. Students experienced that the tutors were of value to them, because they shared their own learning experiences, showed how they themselves had written the bachelor thesis and expressed their confidence that they too could do the job. Students mentioned that they could mirror themselves to the tutors, because tutors knew the struggle of writing a thesis. They felt equality, experienced proximity with the tutor, being of the same generation, recognizing the struggles in their personal situation and the study process.

'It was just very recognizable. You could share your experiences, for every struggle you experienced they told a story about what they had experienced, and they had just made it, so why wouldn't I be able to.' (F)

In addition, tutors were described as actors who provided small talk and a relaxed atmosphere. The fact that tutors graduated with good grades, convinced students that they knew what they were talking about. The alumni developed themselves from student to tutor. This development induced respect for the tutor and the conviction that growth was possible for every student.

\subsubsection{Collaboration}

Sharing means and knowledge. Students described that (group) relationships arose in a formal and informal setting in which students shared knowledge and resources. They shared: 1) personal strategies to finish the bachelor thesis, 2) contacts from their personal and professional network to find a commissioning company, 
respondents or a job, 3) knowledge about research, and 4) teaching materials, and literature.

'It's really interactive. They [teachers and tutor] ask what do you think about it? And you? And tell about your work. Tell me what you did. How is your progress? And what have you done until now? Did you work it out? A lot of questions. And are you running into something? Tell us. Because maybe the rest of us can help you. Come on, people! We will think carefully. We're going to help each other, because we all want to graduate on time. Really so! Then I thought: wooow! All right!'(D)

Students described that there was an information sharing process between the members of the community, asking each other for help and providing help. Students mentioned that they shared written texts, to evaluate how the other person wrote it, and to use each other's perspectives. Students stated that by attending the lectures they were able to give each other feedback. They regarded it satisfying to help others, it gave them a sense of meaning and contributed to their self-esteem.

Informal role-models. Besides formal role models (tutors) also informal role models arose. Students described a process that peers were consciously and unconsciously deployed as role models. This happened first of all because teachers recognised expertise and resources amongst students and linked these students to fellow students to transfer this. The change of roles from student to coach also took place after students got 'a Go' for their research proposal. Making success visible, lead to students appointing each other as a role-model.

'After I received a Go, they [fellow students] thought I could achieve something. So that's why they came to me every time. [..]. How did you do this, how did you do that?' (A)

The same student described:

'I also helped people and because I often was further in the process than most of them, they often came to me and did not have to go to a teacher every time. [..]. Yes, then you learn from each other that is the advantage.' (A) Students indicated that this role-change had a positive impact on their self-esteem.

Social comparison. Social comparison played an important role in the collaboration processes. Students said that they compared themselves with fellow students to check whether they were making sufficient progress. Students wanted to keep affiliation with the group in order not to get behind.

'Hey, it's not going to happen to me that everyone around me, uh, is going to achieve something and I'm still here.' (C)

They therefore worked strictly towards the deadlines. Students said that there was a group culture in which students motivated each other to continue working on the thesis and to deliver. A student said:

'It is motivating that you no longer work individually, but that you see that others are busy and working towards a deadline.' $(\mathrm{H})$

'When I sat at my computer at night, at 3 o'clock p.m. and I noticed in the Facebook group that someone else was busy too. That gave me a boost: hey, I'm not alone. We are all in this together.' (B)

Not every student recognised the benefits of participation in the group. Some students reported that when they saw progress of others and celebration of success, they got stressed and negative feelings regarding their own abilities.

'Well, you heard someone who had writtten something really good. Yes, then I did not have anything on paper yet, so yes, it was sometimes painful. But that was pretty close to the moment I dropped out. So yes, then I was perhaps a bit far away, far away.' (K)

Emotional support and Sociability. In addition, students mentioned they experienced emotional support from each other. They indicated that they could lean on fellow students for things that were stressful and felt that they were not alone. Students mentioned that collaborative learning also entails the function of sociability. Students chatted about non-school matters, made jokes and experienced a cosy atmosphere in the group.

\subsubsection{Mutual Appropriation}

Students described that there was a reciprocal relationship between students and between teachers and students. They described that teachers were complementarity in terms of characteristics, expertise and attitude. Students mentioned teachers exchanged students they guided, if they got stuck in their supervision process. The teachers supported each other in their joint mission to bring students to the finish line. A form of reciprocity arose: if the teacher put a lot of effort in guiding the student, the student put a lot of effort vice versa concerning behaviour to the teacher and also to other students. Students described that the complementarity between students was also present, recognized and used. The recognition that the student contributed expertise and played a significant role 
in the guidance of other students was actively taught by teachers.

'Yes, it would not be fair at all, if the teachers do their best and I would not. '(C)

\subsubsection{Teacher Role}

Teachers played a crucial role in the development of the community identity, the process of collaboration and the individual and collective academic growth of the members of the community. Students who took part in the WBLC described eight roles that the teacher fulfilled and that contributed to further social and academic integration (Table 1).

Table 1. Teacher roles in the WBLC

\begin{tabular}{|c|c|}
\hline Role & Behaviour \\
\hline $\begin{array}{l}\text { 1. Community } \\
\text { /builder }\end{array}$ & $\begin{array}{l}\text { The first role is to strengthen the community identity. Students describe that teachers have } \\
\text { an important role in modelling and securing the 'belief system' in the bounded learning } \\
\text { community. Setting up a culture in which students are addressed as starting professionals, } \\
\text { with high expectations and a high-support structure based on collaboration, faith and mutual } \\
\text { appropriation. Teachers make use of role models in the community. }\end{array}$ \\
\hline 2. Scaffolder & $\begin{array}{l}\text { Students describe a process of scaffolding. They explain that large complex assignments are } \\
\text { divided into separate steps. Students state that the explanation of the teacher simplifies the } \\
\text { process. Students mention that they work with a variety of teaching methods adapted to } \\
\text { students' needs. They describe that they receive assignments that push them to pass mental } \\
\text { thresholds and practice with skills that they experience complicated and difficult. Students } \\
\text { state that they are taken out of their comfort zone. After succeeding in the requested skill, } \\
\text { they experience pride which increases confidence. }\end{array}$ \\
\hline 3. Sup & $\begin{array}{l}\text { Students describe that teachers control and monitor progression. Students are asked where } \\
\text { the students are in the process. In case of insufficient progress, the student is asked to } \\
\text { perform better, and expectations are explicated. Students indicate that this manner of tight } \\
\text { hand is accepted by students, because students experience a good relationship with the } \\
\text { teachers and experience a tangible wish from the teachers that they succeed. }\end{array}$ \\
\hline $\begin{array}{l}\text { 4. Unconditional } \\
\text { supporter }\end{array}$ & $\begin{array}{l}\text { Students experience that teachers unconditionally show commitment and show personal } \\
\text { contact. Students experience that teachers are unconditionally supportive in time and } \\
\text { energy. It is visible that teachers unconditionally support the students as long as the students } \\
\text { put considerable effort in their study programme. They experience interest and sympathy } \\
\text { from the teachers. }\end{array}$ \\
\hline $\begin{array}{l}\text { 5. Builder of } \\
\text { self-esteem }\end{array}$ & $\begin{array}{l}\text { Students mention that teachers encourage self-efficacy, hope, optimism and resilience of } \\
\text { students. They do this by naming the student's skills and qualities, by saying that the student } \\
\text { is capable of achieving the final result, by not only addressing what needs to be corrected, } \\
\text { but also to point out the good things, and by showing what progress has already been made. } \\
\text { The teacher confirms that the student is on the right track, says that the student will succeed, } \\
\text { that nothing is wrong, and that you develop yourself by daring to make mistakes. In } \\
\text { addition, unrealistic thoughts are made discussable, and these are reframed into feasible } \\
\text { thoughts. }\end{array}$ \\
\hline 6. Facilitator & $\begin{array}{l}\text { Teachers actively involve students in giving answers and feedback to others and to share } \\
\text { ideas. The teacher asks how others think about it, points to a shared goal to graduate on } \\
\text { time. Because students are in this position to contribute to the collective, this has an impact } \\
\text { on their self-confidence and growth of academic skills. }\end{array}$ \\
\hline 7. Broker & $\begin{array}{l}\text { The teacher connects people inside and outside the community that can be of mutual } \\
\text { interest. The teacher actively introduces his personal and professional network and provides } \\
\text { alternative respondents for the research. }\end{array}$ \\
\hline 8. Inspirator & $\begin{array}{l}\text { The last role is the teacher as an inspirator. The lectures start with music, which stimulates } \\
\text { the feeling of conviviality. In tutor meetings there is room for small talk. Students describe } \\
\text { the teachers as enthusiastic and involved and notice that teachers have a passion for the } \\
\text { content they are teaching. The teachers visibly have fun in guiding the groups. }\end{array}$ \\
\hline
\end{tabular}

\section{Conclusion}

We investigated the elements of a warm bounded learning community (WBLC) that contribute to student 
engagement, and social and academic reintegration, in order for students with a study delay to overcome barriers for successful graduation. The following elements appear to be crucial in the design of such a learning environment:

- community structure: all members of the (sub)group(s) meet frequently in a shared physical (and digital) environment simultaneously;

- community culture: in the design, values such as strength, high expectations, belief in the student and learning from and with each other, should be expressed in language, routines, symbols and rituals;

- mechanisms of collaborative learning within the community as a whole, and within the separate subgroups: the group composition based on shared goals, equal phase of process and complementarity skills is preferable, in order to initiate the process of reciprocity (social interdependence), sharing means and knowledge (resource interdependence);

- scaffolding: the design of the learning environment requires a clear structure in which complex tasks takes are divided into smaller sub tasks; strong steering in the beginning gradually decreasing to more independence towards the end of the process;

- role models: role models assigned by the teachers that play a formal role in guiding groups of students, and informal role models that arise in the groups because teachers recognise expertise and talents in students and set these students as an example;

- teachers' roles: 'community builder', 'scaffolder', 'supervisor', 'unconditional supporter', 'builder of self-esteem', 'facilitator', 'broker' and 'inspirator'.

\section{Discussion}

\subsection{Barriers}

Students described two levels of barriers that prevented them from finalising their bachelor programme. On a personal level they experienced competing obligations, a lack of academic skills, and nonalignment of previous expectations of their study programme and their future profession. On the institutional level, students experienced a gap between their study trajectory and new graduation demands, teachers lacking guiding skills, stigmatisation by the institution, and a curriculum design that forced them to work individually without social support.

We conclude that students with a study delay were faced with isolation and detachment from personal goals, fellow students and the university. This led to declining self-confidence and diminished mental resilience. Georg (2009) also found that dropping out has an impact on students' personality, capabilities for achievement, and academic self-concept. This is explained by the expectation of success by their social context and the weak commitment to their study programme in general or the specific field of study.

\subsection{Mechanisms Contributing to Social Integration}

The results of this study indicate that these students with a study delay can identify themselves with several aspects of the learning environment and experience peer interdependence, this positively impacts their engagement and social integration. Connecting with peers in a physical environment, frequent contact moments with students and teachers, having shared goals and recognizing themselves in role models, contributed to this engagement and integration. A shared history of study delay reinforced this identification. Students' sense of belonging was increased by creating a strong group culture (community identity) designed according to the premises of collaborative learning. This stimulated social comparison, group pressure, emotional support and sociability. These findings are in line with findings of Barab and Duffy (2000) who state that common cultural and historical heritage including shared goals, meaning and practices in an interdependent system, are interconnecting the community.

Similar to Wilson et al., (2004) we conclude that transformation rituals (like visualising the collective progress) positively impact identification with the learning community. Students perceived group participation as conditional for achieving academic success. Brouwer (2017) found that group pressure and social comparison is not perceived positively by every student. We found that social integration was hindered by students that have difficulty to conform to the strict rules of the programme regarding attendance and involvement. Social integration also stagnated when students felt they were unable to keep up with the achievements of other students.

We conclude that social integration and psychological resilience of students with a study delay was strengthened by the WBLC. Teachers contributed to the social integration of student performing the role of "community 
builder', 'unconditional supporter' and 'inspirator'.

\subsection{Mechanisms Contributing to Academic Integration}

Students described that the community structure in which they renew their social ties with the university, contributes to academic integration. Students stated that it is satisfactory and meaningful to support other students. Helping other students enhanced task pleasure, enlarged self-confidence and motivation to finish the task.

Sharing means and knowledge (resource interdependence) contributed to bridging the gap of academic knowledge and skills. Academic integration was strengthened by the availability and transfer of complementary expertise of the group members. Students experienced they can benefit from multiple perspectives. Similarly, research on collaboration also indicates that diversity of expertise leads to academic growth by solving individual questions, obstacles and dilemmas of delayed and long-term students through collective knowledge (Bielaczyz \& Collins, 1999; Johnson \& Johnson, 2008).

Role models contributed to academic integration as well. Both formal and informal role models showed how to pursue goals, how to divide the process into separate manageable steps, and how to be persistent. Student that grew to be informal role models, reinforced their academic self-esteem and got more actively involved in their own learning process and that of their peers. They gained a trust in the possibility of academic growth. Academic integration was supported by the teacher in the role of 'community builder', 'scaffolder', 'supervisor', 'builder of self-esteem', 'facilitator', 'broker' and 'inspirator'.

\subsection{Limitations and Further Research}

The respondents were all students of a university of applied sciences in a large city in the Netherlands. This university houses students with a variety of ethnic and cultural backgrounds. Furthermore, they differ regarding prior qualifications and academic preparedness. In universities with a more homogeneous population there may be another fit between student habitus and institutional habitus. This may require different approaches to support students with a study delay. A similar study in a university with a more homogeneous student population may provide more insight in the generalisability of the barriers students experience.

We used in depth interviews that only represent the perception of the interaction that took place between students and teachers. For future research we suggest including observations during the group sessions, to complement the data.

Bias that may have influenced our results, is that students we interviewed participated in almost all of meetings of the new project. Early dropouts were not asked to participate. They may have answered differently.

\section{Concluding Remark}

Our research indicates that a WBLC is conditional to transform students with a study delay into successful students, whereby the W from "warm" is a crucial element of the community. This is congruent with the slogan of the researched WBLC: 'Graduation is a joint experience!'.

\section{References}

Altbach, P. G., Reisberg, L., \& Rumbley, L. E. (2009). Trends in global higher education: Tracking an academic revolution. A report prepared for the UNESCO 2009 World conference on higher education. https://doi.org/10.1163/9789004406155

Atkinson, R. (1998). The life story interview. Thousand Oaks, CA: Sage. https://doi.org/10.4135/9781412986205

Barab, S. A., \& Duffy, T. M. (2000). From practice fields to communities of practice. In D. H. Jonassen \& S. M. Land (Eds.), Theoretical foundations of learning environments (pp. 25-55). Mahwah, NJ: Lawrence Erlbaum Associates Publishers.

Bourdieu, P., \& Passeron, J. C. (1977). Reproduction in education, society and culture. London \& Beverly Hills: Sage Publications.

Brouwer, J. (2017). Connecting, interacting and supporting: Social capital, peer network and cognitive perspectives on small group teaching. Groningen: Rijksuniversiteit Groningen.

Bielaczyc, K., \& Collins, A. (1999). Learning communities in classrooms: A reconceptualisation of educational practice. In C. M. Reigeluth (Ed.), Instructional design theories and models, Vol. II. Mahwah NJ: Lawrence Erlbaum Associates.

Chickering, A. W., \& Gamson, Z. F. (1987). Seven principles for good practice in undergraduate education. 
American Association of Higher Education Bulletin, 39(7), 3-7.

Flanagan, J. C. (1954). The Critical Incident Technique. Psychological Bulletin, 5, 327-358. https://doi.org/10.1037/h0061470

Fransen, J., Weinberger, A., \& Kirschner, P. A. (2013). Team Effectiveness and Team Development in CSCL. Educational Psychologist, 48(1), 9-24. https://doi.org/10.1080/00461520.2012.747947

Georg, W. (2009). Individual and institutional factors in the tendency to drop out of higher education: a multilevel analysis using data from the Konstanz Student Survey. Studies in Higher Education, 34(6), 647-661. https://doi.org/10.1080/03075070802592730

Ho, J. C. W., Wong, L. J. C., \& Wong, P. T. P. (2010). What helps and hinders thesis completion: A critical incident study. International Journal of Existential Psychology \& Psychotherapy, 3(2), 117-131.

Johnson, D. W., \& Johnson, R. T. (2008). Social interdependence theory and cooperative learning: The teacher's role. In R. M. Gillies, A. F. Ashman \& J. Terwel (Eds.), The teacher's role in implementing cooperative learning in the classroom: An introduction (pp. 9-37). New York, U.S.A.: Springer. https://doi.org/10.1007/978-0-387-70892-8_1

Kahu, E. R. (2013). Framing student engagement in higher education. Studies in Higher Education, 38(5), 758-773. https://doi.org/10.1080/03075079.2011.598505

Marble, S. (1997). Narrative visions of schooling. Teaching and Teacher Education, 13(1), 55-64. https://doi.org/10.1016/S0742-051X(96)00043-1

Ryan, M., \& Deci, E. L. (2000). Intrinsic and extrinsic motivations: Classic definitions and new directions. Contemporary Educational Psychology, 25, 54-67. https://doi.org/10.1006/ceps.1999.1020

Skinner, E. A. (2012). Intrinsic motivation and engagement as 'Active ingredients' in garden-based education: Examining models and measures derived from self-determination theory. The Journal of Environmental Education, 43(1), 16-36. https://doi.org/10.1080/00958964.2011.596856

Skinner, E. A. (2016). Engagement and disaffection as central to processes of motivational resilience and development. In K. R. Wentzel \& D. B. Miele (Eds.), Handbook of motivation at school (pp. 145-168). New York: Routledge.

Thomas, L. (2002). Student retention in higher education: The role of institutional habitus. Journal of Education Policy, 17(4), 423-432. https://doi.org/10.1080/02680930210140257

Tinto, V. (1975). Dropouts from higher education: A theoretical synthesis of the recent literature. A Review of Educational Research, 45, 89-125. https://doi.org/10.3102/00346543045001089

Tinto, V. (1997) Classrooms as communities: exploring the educational character of student persistence, Journal of Higher Education, 68(6), 599-623. https://doi.org/10.1080/00221546.1997.11779003

Tinto, V. (2012). Completing college: Rethinking institutional action. Chicago: University of Chicago Press. https://doi.org/10.7208/chicago/9780226804545.001.0001

Wilson, B. G., Ludwig-Hardman, S., Thornam, C. L., \& Dunlap, J. C. (2004). Bounded learning communities: Designing and facilitating learning communities in formal courses. International Review of Research in Open and Distance Learning, 5(3), 1-22. https://doi.org/10.19173/irrodl.v5i3.204

\section{Copyrights}

Copyright for this article is retained by the author(s), with first publication rights granted to the journal.

This is an open-access article distributed under the terms and conditions of the Creative Commons Attribution license (http://creativecommons.org/licenses/by/4.0/). 